\title{
Índice de pobreza multidimensional do nordeste brasileiro: uma análise no período
}

\section{de 2009-2015}

\author{
Multidimensional poverty index of northeast Brazil: an analysis in the period 2009-2015 \\ Índice de pobreza multidimensional del noreste de Brasil: un análisis en el período 2009-2015
}

Erika Costa Sousa

ORCID: https://orcid.org/0000-0003-3267-2779 Universidade Federal do Ceará, Brasil E-mail: erikacosta115@gmail.com

Janaildo Soares de Sousa

ORCID: https://orcid.org/0000-0002-3380-5660 Universidade Federal do Ceará, Brasil E-mail: janaildo18@hotmail.com

Eucinete de Menezes Albuquerque ORCID: https://orcid.org/0000-0002-9351-1832 Universidade Federal do Ceará, Brasil E-mail: eucinetemenezes@gmail.com

Laura Cunha Rebouças Lessa ORCID: https://orcid.org/0000-0002-5000-3002 Universidade Federal do Ceará, Brasil E-mail:laura_crlessa@alu.ufc.br

José Natanael Fontenele de Carvalho ORCID: https://orcid.org/0000-0003-3748-390X

Universidade Federal do Delta do Parnaíba, Brasil E-mail: natanaelfontenele@ufpi.edu.br

\begin{abstract}
Resumo
O presente estudo tem como objetivo mensurar o nível de pobreza multidimensional dos estados nordestinos no período de 2009 a 2015. Como estratégia empírica adota-se a criação do Índice de Pobreza Multidimensional da Região Nordeste - IPMNE dos estados nordestinos. Para tanto, utiliza a metodologia construída por Bourguignon e Chakravarty (2019), adaptada por Silva et al (2016). Para a construção do IPMNE são utilizados os micro-dados da Pesquisa Nacional por Amostra de Domicílio (PNAD) dos respectivos anos. Os resultados das seis dimensões evidenciam uma redução da proporção da pobreza multidimensional da população nordestina. No entanto, três merecem uma atenção maior: (i) Educação; (ii) Comunicação e Informação e (iii) Trabalho e Demografia. No tocante as análises isoladas das regiões metropolitana, urbana e rural, verificou-se que a pobreza foi mais intensa na área rural. Portanto, o presente estudo pode ser utilizado para auxiliar futuras políticas públicas de redistribuição de renda da Região Nordeste.
\end{abstract}

Palavras-chave: Pobreza; Pobreza multidimensional; Privação.

\begin{abstract}
The present study aims to measure the multidimensional poverty level of the northeastern states from 2009 to 2015 . As an empirical strategy we adopt the creation of the Multidimensional Poverty Index of the Northeast - IPMNE of the northeastern states. To this end, it uses the methodology built by Bourguignon and Chakravarty (2003), adapted by Silva et al (2016). For the construction of the IPMNE, we use the data from the National Household Sample Survey (PNAD) from the respective years. The results of the six dimensions show a reduction in the proportion of the multidimensional poverty of the northeastern population. However, three deserve greater attention: (i) Education; (ii) Communication and Information and (iii) Work and Demography. Regarding the isolated analyzes of the metropolitan, urban and rural regions, it was found that poverty was more intense in the rural area. Therefore, the present study can be used to help future public income redistribution policies of the Northeast Region.
\end{abstract}

Keywords: Poverty; Multidimensional poverty; Deprivation.

\section{Resumen}

Este estudio tiene como objetivo medir el nivel de pobreza multidimensional en los estados del noreste en el período de 2009 a 2015. Como estrategia empírica, se adopta la creación del Índice de Pobreza Multidimensional de la Región Noreste - IPMNE en los estados del noreste. Para ello, utiliza la metodología construida por Bourguignon y Chakravarty (2003), adaptada por Silva et al (2016). Para la construcción del IPMNE se utilizan microdatos de la 
Encuesta Nacional por Muestras de Hogares (PNAD) de los años respectivos. Los resultados de las seis dimensiones muestran una reducción en la proporción de pobreza multidimensional de la población nororiental. Sin embargo, tres merecen mayor atención: (i) Educación; (ii) Comunicación e Información y (iii) Laboral y Demografía. En cuanto a los análisis aislados de las regiones metropolitana, urbana y rural, se encontró que la pobreza era más intensa en el área rural. Por lo tanto, el presente estudio puede ser utilizado para ayudar a futuras políticas públicas de redistribución del ingreso en la Región Nordeste.

Palabras clave: Pobreza; Pobreza multidimensional; Privación.

\section{Introdução}

A pobreza na Região Nordeste do Brasil sempre foi e continua sendo pauta de debates de autores de diversas áreas. Josué de Castro, geógrafo, por exemplo, evidenciou bem a realidade das privações do Nordeste açucareiro em “Geografia da Fome”, quando concluiu que a privação de renda comprometia a dieta calórica minimamente digna para os nordestinos, como consequência apresentava formas endêmicas de carências nutricionais, a saber: i) carências proteicas; ii) carência das de vitaminas A, B1 e B2; e iii) carências dos minerais ferro e cloreto de sódio (Castro, 1980; Vasconcelos, 2008; Caetano; Castro, 2021).

Observa-se a partir desse contexto uma espiral de problemas ocasionados pela privação de renda do sertanejo, a saber: i) sem a renda necessária para demandar uma cesta de bens ideal para suprir as necessidades calóricas, as pessoas podem adoecer; ii) adoecendo, passam a não ter como trabalhar e, consequentemente, menos renda, é o caso das pessoas que possuem trabalho precário; iii) com as limitações laborais em virtude das doenças, a carência dos insumos necessários para uma dieta calórica digna é maximizada; e iv) em virtude da intercorrência da saúde os indivíduos precisam de cuidados especiais e uma alimentação saudável, mas ambos são comprometidos por causa da privação de renda, ficando privados da liberdade de escolha entre trabalhar e se recuperar de uma determinada patologia. Essa espiral de problemas ocasionados pela privação de renda só reforça a máxima: a pobreza multidimensional impede de as pessoas terem acesso aos funcionamentos básicos emanados pela Constituição Federal (CF) de 1988, e conflui para o círculo vicioso da pobreza.

Segundo o Relatório do Banco Mundial (1990), a pobreza multidimensional pode ser definida a partir de situações de privação em vários aspectos da vida, como de quem passa fome, carece de habitação e vestuário, estar doente e não tem condições econômicas para se tratar, e é analfabeto e não tem meios para conseguir a escolarização. Em suma, o conceito de pobreza vai muito além de privação de renda, tendo em vista que se define pobreza como incapacidade de ter condições mínimas de qualidade de vida. Visto que, por muito tempo, a pobreza foi medida apenas como escassez de renda, "pois, por simplificação, a renda representa um meio para adquirir bens essenciais para sobrevivência” (Caldas; Sampaio, 2015, p. 76).

No entanto, mensurar a pobreza via a abordagem unidimensional (privação de renda) esmaece o retrato da pobreza de um País, Região, Estado ou Município, uma vez que a pessoa pode ser pobre por não ter acesso aos serviços básicos como: água encanada, saúde, educação, segurança, habitação, saneamento básico, dentre outros. Essa condição corrobora com o pensamento de Kageyama e Hoffmann (2006), quando afirmam que é preciso considerar que a pobreza é um fenômeno multidimensional, pois a partir dessa análise é possível identificar de fato os reais níveis de privação dos indivíduos, bem como as dimensões em que eles mais se concentram, evitando pormenorizar o nível de pobreza de cada domicílio.

Para Kageyama e Hollfmann (2006, p. 84), a pobreza multidimensional “[...] impõe privações em condições básicas de existência, como luz elétrica, água encanada e instalações sanitárias, e dificuldade de acesso aos serviços de saúde e educação [...]”. Ou seja, a pobreza não pode ser vista e mensurada apenas pela ótica da privação de renda, tendo em vista que os aspectos reportados intensificam o nível de pobreza das famílias e, portanto, enviesam a situação da pobreza.

Dentre as regiões brasileiras, “[...] a situação da pobreza é mais grave nas regiões Norte e Nordeste do Brasil”. (Silva et al, 2016, p. 16) e, dessa forma, merecem atenção mais austera em termos de análise de seus indicadores e das respectivas dimensões, bem como na elaboração de políticas públicas sociais mais enérgicas que englobem as especificidades regionais. Já 
que, "interpretar a pobreza como um fenômeno multidimensional é atribuir importância às políticas sociais, que precisam atuar em conjunto, de forma não somente a retirar o indivíduo da pobreza, mas também de evitar o seu retorno a ela" (Silva et al, 2011, p.524).

O Nordeste brasileiro trata-se de uma Região que ainda apresenta baixos níveis de desenvolvimento e, dessa forma, merece uma atenção minuciosa em termos de análise de seus indicadores e das respectivas políticas públicas que venham contribuir para o arrefecimento dos entraves da redução da miséria. "Diante disso, surge a importância da mensuração da pobreza no Nordeste brasileiro não apenas pela ótica da renda. É necessário, portanto, ampliar o estudo para o atendimento das necessidades básicas e incrementar a definição de pobreza um caráter multidimensional [...]”" (Silva; Araújo; Justo; Campos, 2017). Desse modo, torna-se preponderante a análise da pobreza além da privação de renda.

Esse contexto instiga uma série de questionamentos, mas o presente estudo centra-se em dois deles: (i) qual o nível da pobreza multidimensional dos estados nordestinos no período de 2009 a 2015?; e (ii) em quais dimensões apresentam-se os maiores níveis de privação. Desse modo, o presente trabalho tem por objetivo analisar o nível da pobreza multidimensional dos estados nordestinos no período de 2009 a 2015². Especificamente tem-se: (i) criar o Índice de Pobreza Multidimensional do Nordeste - IPMNE para o período de 2009 a 2015 e (ii) Examinar o nível de privação da pobreza por estados e grupos da Região Nordeste no período de 2009 a 2015. As respostas a esses questionamentos e o alcance dos objetivos ora propostos demandam de análises multidimensionais e, portanto, buscando alcançá-los é construído o Índice de Pobreza Multidimensional da Região Nordeste - IPMNE, método inovador, construído por Bourguignon e Chakravarty (2019) e adaptado por Silva et al (2016).

O interesse em avançar nessa análise pode ser justificado por alguns motivos, a saber: (i) não se verificou na literatura estudos que abordem a pobreza multidimensional no período em análise; (ii) a redução da pobreza e desigualdade de renda desempenham um papel importante no crescimento e desenvolvimento econômico (Sen, 1996; Kageyama; Hoffmann, 2006); (iii) por a redução da pobreza ter sido integrada como uma das metas dos Objetivos do Desenvolvimento Sustentável - ODS² e (iv) dado que a Região Nordeste do Brasil ainda apresenta níveis alarmantes de incidência de pobreza, visto que buscar a redução de tais níveis de privações resultará em uma redução da desigualdade regional da pobreza e, portanto, passa a ser uma estratégia plausível (Rocha 1995; Kageyama; Hoffmann, 2006; Silva; Sousa; Araújo, 2017).

Ao discutir sobre os níveis de privação da Região Nordeste no período de 2009 a 2015, sob a perspectiva multidimensional, o artigo traz pelo menos duas contribuições relevantes. A primeira, diz respeito à produção do diagnóstico da situação dos estados nordestinos no tocante ao nível de pobreza multidimensional recente, podendo ser utilizado como prognóstico para a formulação de políticas e estratégias de combate à pobreza na respectiva região. Essa contribuição é importante porque serve de instrumento para uma melhor compreensão do nível de pobreza multidimensional dos estados nordestinos, realidade essa que poderá contribuir para os policymakers ao elaborarem políticas mais efetivas, evitando considerar apenas o indicador renda. À segunda por evidenciar as dimensões que mais impactam a pobreza multidimensional no Nordeste brasileiro. Esse contributo é preponderante pelo fato de evidenciar as assimetrias estaduais dos estados nordestinos, bem como as suas especificidades intrarregionais e, por fim, comprovar as alteridades do urbano, rural e área metropolitana do Nordeste do Brasil.

\footnotetext{
${ }^{1}$ A análise ficou restrita até 2015 pelo fato de que após o ano de 2015, o Instituto Brasileiro de Geografia e Estatística - IBGE não disponibiliza mais a PNAD anual, somente a contínua.

${ }^{2}$ Trata-se de uma agenda global reestabelecida com base nos ODMs e tem por objetivo promover o desenvolvimento econômico, social e ambiental de forma sustentável até 2030. Para isso, será necessário atingir seus dezessete objetivos e, dentre eles, o terceiro, o qual engloba a erradicação da mortalidade infantil (Pnud, 2016).
} 
Além desta introdução, o presente artigo apresenta mais três seções: (ii) apresentação dos procedimentos metodológicos empregados para o alcance dos objetivos propostos; (iii) análise e discussão dos resultados e, por fim, (iv) as considerações do estudo.

\section{Metodologia}

O presente estudo é quantitativo, levando em consideração a abordagem do problema e, portanto, traz os indicadores como informação para a tomada de decisão de políticas públicas. Ademais, faz o uso de técnicas estatísticas (Prodanov; Freitas, 2013).

O presente estudo adotou como unidade de observação os estados nordestinos. A escolha em adotar a Região Nordeste partiu da constatação de que a pobreza multidimensional é mais grave na Região Norte e Nordeste (Silva et al, 2016), portanto, analisar o comportamento da pobreza na Região Nordeste, especificamente, é um passo inicial para propor alternativas que reduzam os níveis de privação dos indivíduos que residem nessa unidade de observação.

O IPM - NE é formado por 6 dimensões e 22 variáveis (Figura 1) que são oriundas dos micro-dados da Pesquisa Nacional por Amostra de Domicílios (PNAD), referentes aos anos de 2009 a 2015, exceto 2010, por ser um ano em que ocorreu o Censo e, portanto, não há PNAD para o respectivo ano. A escolha de cada uma das variáveis e das respectivas dimensões foram embasadas a partir na revisão da literatura a respeito da temática da pobreza, conforme evidencia a Tabela 1. O uso de índices e indicadores de pobreza multidimensional são ferramentas essenciais para auxiliar a administração pública no desenvolvimento de políticas que combatam a pobreza em todas as suas dimensões (Silva et al, 2016; Silva; Sousa; Araújo, 2017; Torres et al., 2020).

A Tabela 1 mostra os indicadores $X_{i, k}^{1}$ construídos para $\mathrm{i}=\{1,2, \ldots, \mathrm{n}\}$ pessoas, $\mathrm{j}=\{1,2, \ldots, \mathrm{h}\}$ domicílios e $\mathrm{k}=\{1,2, \ldots, \mathrm{m}\}$ dimensões. Todos os indicadores têm valor máximo de 1 (não privado) e mínimo de 0 (privação total). Os indicadores são determinados por um intervalo, entre 0 e 1 para diminuir os problemas de descontinuidade, mas são limitados pela informação disponível. Com o intuito de obter distintos conjuntos de dados categóricos, foram estabelecidos diferentes níveis equidistantes (ou seja, os indicadores são ordinais).

Em cada dimensão há uma agregação de indicadores sobre a base da seguinte função: $X_{i, k}=g_{k}\left(X_{i, k}^{1}, \ldots, X_{i, k}^{P}\right)=g_{k}\left(X_{i, k}^{1}, \ldots, X_{i, k}^{P}\right)$ para as variáveis $l=\{1, \ldots, p\}$, onde a função $g_{k}(\cdot) g_{k}(\cdot)$ é específica de cada dimensão $k$. Para identificar o nível de privação de cada dimensão, realiza-se a reformulação dos índices utilizando-se a fórmula: $\hat{X}_{i, k}=1-X_{i, k} \quad \hat{X}_{i, k}=1-X_{i, k}$, onde o nível de privação $\hat{x}_{i, k} \hat{x}_{i, k}$ é interpretado como sendo o Gap relativo entre o nível individual de $X_{k} X_{k}$ e o limiar da privação $z_{k}=1 \quad Z_{k}=1$, sendo que este tem valor máximo de 1 (privação total) e mínimo de 0 (sem privação) 
Tabela 1 - Dimensões e indicadores da pobreza multidimensional.

\begin{tabular}{|c|c|c|c|}
\hline Dimensões & Variáveis Derivadas & Indicadores & Justificativa teórica \\
\hline & Água na Moradia & $X_{i, 1}^{1}=\left\{\begin{array}{l}1, \text { se sim } \\
0, \text { se não }\end{array}\right.$ & $\begin{array}{l}\text { "A variável água mede se há } \\
\text { abastecimento de água apropriada na } \\
\text { moradia." (Leite et al, 2016). }\end{array}$ \\
\hline Alimentos e Água & $\begin{array}{l}\text { Capacidade de compra } \\
\text { de alimentos }\end{array}$ & $X_{i, 1}^{2}=\min \left\{1, \frac{\text { renda per capita } a_{j i \in} \in J}{\text { linha de pobreza }}\right\}$ & $\begin{array}{l}\text { "A variável capacidade de compra de } \\
\text { alimentos, por meio da condição } \\
\text { monetária, faz uma relação da renda per } \\
\text { capita do indivíduo com a linha de } \\
\text { pobreza de renda. As linhas de pobreza } \\
\text { utilizadas foram do Instituto de Estudo } \\
\text { do Trabalho e Sociedade (Iets), } \\
\text { elaboração de Sonia Rocha com base na } \\
\text { Pesquisa de Orçamento Familiar (POF)." } \\
\text { (Leite et al, 2016). }\end{array}$ \\
\hline
\end{tabular}

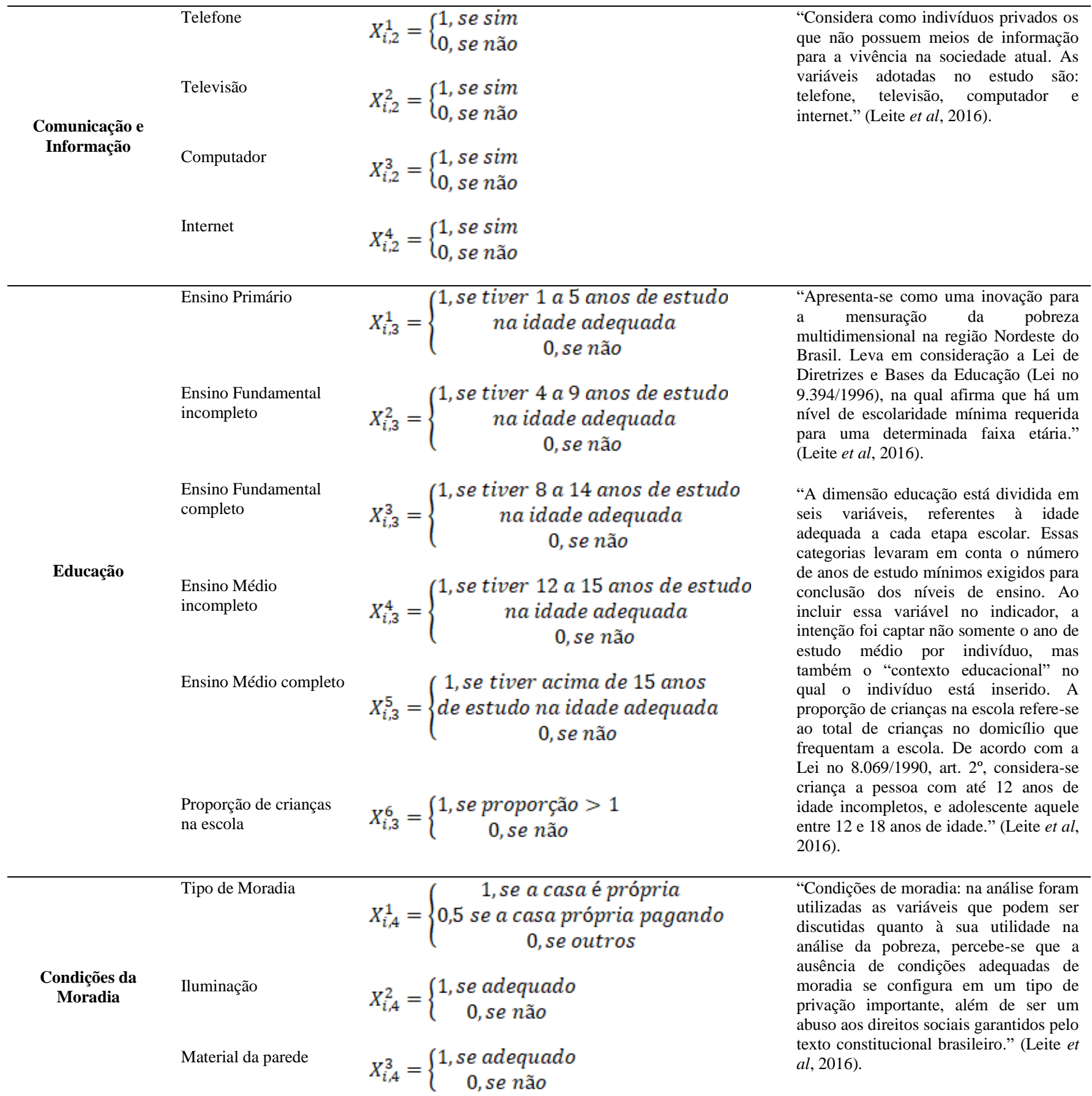




\begin{tabular}{|c|c|c|c|}
\hline & Material do teto & \multicolumn{2}{|l|}{$X_{i, 4}^{4}=\left\{\begin{array}{c}1, \text { se adequado } \\
0, \text { se não }\end{array}\right.$} \\
\hline & $\begin{array}{l}\mathrm{N}^{\circ} \text { de pessoas por } \\
\text { dormitório }\end{array}$ & $X_{i, 5}^{5}=\left\{\begin{array}{l}1, \text { se }<3 \\
0, \text { se não }\end{array}\right.$ & \\
\hline Saúde & $\begin{array}{l}\text { Esgotamento sanitário } \\
\text { Condição Sanitária } \\
\text { Eliminação do lixo }\end{array}$ & $\begin{array}{l}X_{i, 5}^{1}=\left\{\begin{array}{c}1, \text { se adequado } \\
0, \text { se não }\end{array}\right. \\
X_{i, 5}^{2}=\left\{\begin{array}{c}1, \text { se adequado } \\
0, \text { se não }\end{array}\right. \\
X_{i, 5}^{3}=\left\{\begin{array}{c}1, \text { se adequado } \\
0, \text { se não }\end{array}\right.\end{array}$ & $\begin{array}{l}\text { "Como não existem variáveis específicas } \\
\text { que possam trazer informações a respeito } \\
\text { dessa dimensão no período em estudo, } \\
\text { utilizou-se proxies. A justificativa para } \\
\text { essa escolha foi o entendimento de que a } \\
\text { falta de acesso ou o acesso inapropriado } \\
\text { a qualquer uma dessas variáveis pode } \\
\text { ocasionar sérios prejuízos à saúde do } \\
\text { indivíduo, principalmente no que diz } \\
\text { respeito à saúde básica." (Leite et al, } \\
\text { 2016). }\end{array}$ \\
\hline $\begin{array}{l}\text { Trabalho e } \\
\text { Demografia }\end{array}$ & $\begin{array}{l}\text { Razão de dependência } \\
\text { por domicílio }\end{array}$ & $\begin{array}{l}X_{i, 6}^{1}=\left\{\begin{array}{l}1, \text { se não } \\
0, \text { se sim }\end{array}\right. \\
X_{i, 6}^{2}=\left\{\begin{array}{c}1, \text { se proporção }<1 \\
0, \text { se não }\end{array}\right.\end{array}$ & $\begin{array}{l}\text { "Classificou-se como situação de } \\
\text { trabalho precário aquela na qual o } \\
\text { trabalhador não era segurado da } \\
\text { previdência social nem contribuinte de } \\
\text { outro instituto de previdência e, por isso, } \\
\text { não tinha proteção contra os chamados } \\
\text { riscos sociais (incapacitantes ao } \\
\text { trabalho)." (Leite } \text { et al, 2016). }\end{array}$ \\
\hline
\end{tabular}

Fonte: Elaboração própria a partir dos dados da PNADs (2009 a 2015).

Em cada dimensão busca-se analisar o nível de privação dos indivíduos. No caso da Dimensão 1 - Alimentos e Água por exemplo, é composta por duas varáveis: água na moradia e capacidade de compra de alimentos. Água na moradia é definida como bem de necessidade básica para a sobrevivência humana e sua proveniência nos domicílios mede a privação ou não da população. O domicílio é classificado privado se a água do mesmo for proveniente de poço ou nascente, outra providência. É classificado não privado, caso o abastecimento ocorra por meio da rede geral de distribuição.

Vale ressaltar que a variável capacidade de compra de alimentos mensura a privação monetária (ou seja, a renda), como um substituto para a privação de alimentos. Os domicílios com renda per capita inferior à linha de pobreza é classificado privado, por não ser capaz de suprir necessidades nutricionais mínimas. As linhas de pobreza utilizadas foram aquelas do Instituto de Estudo do Trabalho e Sociedade (IETS), elaborado por Rocha (2006), com base na Pesquisa de Orçamento Familiar (POF).

Na Dimensão 2 - busca-se analisar o nível de privação no tocante a comunicação e informação. A referida dimensão é composta de quatro indicadores, a saber: telefone, televisão, computador e internet. Nesse caso são considerados como privados os indivíduos que não possuem nenhum dos meios de informação e comunicação no seu referido domicílio.

No caso da Dimensão 3 - Educação há uma ressalva a ser feita. Nesse caso é levado em consideração as prerrogativas da Lei de Diretrizes e Bases da Educação (Lei 9.394/1996), a qual estabelece um nível de escolaridade mínimo requerido para uma determinada faixa etária. Conforme o disposto na Lei, no ensino primário, as crianças com até 5 anos de idade, podem ter, no máximo, 5 anos de escolaridade, denominado ensino pré-escolar. No ensino fundamental incompleto, crianças de 6 anos a 10 anos de idade, devem ter entre 4 a 9 anos de estudo, para não serem caracterizados como privados. No ensino fundamental completo, seriam as crianças de 11 a 14 anos que estariam terminando o ensino fundamental, em torno de 8 a 14 anos de escolaridade.

Além disso, para que os pré-adolescentes não sejam caracterizados como privados de educação, a Lei emana que a faixa etária para estarem com o ensino médio incompleto se dá entre 12 a 15 anos de estudo, enquanto que para a sua conclusão é preciso ter no mínimo 15 anos de escolaridade. Dessa forma, os jovens terão sua formação, além de estarem aptos a ingressarem no mercado de trabalho. 
A referida dimensão compreende 6 indicadores, os quais foram analisados a partir da idade adequada referente a cada etapa escolar: Ensino primário, Ensino Fundamental incompleto e completo, Ensino Médio incompleto e completo. Nessas categorias, levou-se em conta o número de anos de estudo mínimos exigidos para conclusão dos níveis de ensino. A intenção em introduzir essa variável no IPM foi de captar, não somente o ano de estudo médio por indivíduo, mas também o "contexto educacional" no qual o indivíduo está inserido.

No caso da proporção de crianças da escola faz-se uma relação do total de crianças no domicílio, buscando identificar se houve um aumento de crianças com acesso à educação. De acordo com o art. $2^{\circ}$ da Lei ${ }^{\circ}$ 8.069/90, considera-se criança a pessoa de até 12 anos de idade incompletos e adolescentes, aquela entre doze e dezoito anos de idade.

A Dimensão 4 - Moradia, por sua vez, foi incluída no intuito de verificar o nível de privação dos nordestinos no tocante às condições de moradia. "A habitação - "espaço onde a função principal é ter a qualidade de ser habitável" abrange múltiplas dimensões, destacando-se a física, a cultural, a econômica, a ecológica e a sanitária" (Magalhães et al, 2013, p.59). Além disso, "a habitação deve apresentar condições mínimas que contribuam para saúde e bem-estar de seus membros e para dignidade humana” (Magalhães et al, 2013, 2013, p. 59). Na referida dimensão foram utilizados os seguintes indicadores para verificar o nível de privação: tipo de moradia, iluminação, material de parede, material do teto e número de pessoas por dormitório. Ainda que essas variáveis possam ser discutidas quanto à sua utilidade na análise da pobreza, percebe-se que a ausência de condições adequadas de moradia se configura em um tipo de privação importante, além de ser uma violação dos direitos sociais emanados pelo texto constitucional brasileiro.

Vale destacar que a "Declaração Universal dos Direitos do Homem reconhece o direito à moradia adequada como essencial para um padrão de vida digno. No Brasil, a Constituição Federal também incluiu a moradia entre os direitos sociais mínimos, prevendo a promoção de programas de habitação e saneamento básico pelas três esferas do governo" (MORAIS, 2002, p. 109).

Por fim, tem-se a Dimensão 5 - Trabalho e Demografia, a qual leva em consideração que a situação de trabalho precário é aquela na qual o trabalhador não era segurado da Previdência Social, nem contribuinte de outro Instituto de Previdência e, por isso, não tinha proteção contra os chamados riscos sociais (incapacitantes ao trabalho). Além disso, utilizase a variável razão de dependência, a qual se trata de um indicador demográfico utilizado nas análises de mercado de trabalho e mostra a relação entre o número de pessoas em idade potencialmente inativa e ativa. Nesse sentido, Oliveira (2016) destaca que o trabalho precário é ainda uma situação recorrente na Região Nordeste.

\subsection{Indicador de pobreza multidimensional}

Ser privado das necessidades básicas é, para Sen (2000), ser pobre. Além disso, conforme Bourguignon e Chakravarty (2019), uma forma trivial de definir a pobreza e a contagem do número de pobres é levar em consideração a possibilidade de ser pobre em qualquer dimensão da pobreza. Uma opção de operacionalizar isso é definir a variável indicador de pobreza. O IPM define a pobreza mediante um vetor de características particulares (Tsui, 2002).

Desse modo, um índice de pobreza multidimensional pode ser apresentado como a seguinte função:

$$
P(X, z): M X z \rightarrow R_{+}^{1}
$$

Em que $X \in M \quad X \in M$ é uma matriz de atributos, como renda, educação, saúde, $(n \times m)$, para $i=\{1,2, \ldots, m\}$ pessoas e $k=\{1,2, \ldots, m\}$ dimensões, $z \in Z$ é um vetor de limites ou "níveis minimamente aceitáveis" para diferentes atributos (Bourguignon; Chakravarty, 2003). 
Há várias formas para se mensurar o nível de pobreza multidimensional de uma região ou país. Um método que vem sendo bastante difundido é o IPM. A construção de um índice pode ser definida por meio de pelo menos três diferentes abordagens metodológicas: a abordagem axiomática, a teoria dos conjuntos fuzzy e a teoria das informações (MAASOUMI e LUGO, 2008). No presente estudo utiliza-se a abordagem axiomática, a qual foi iniciada por Sen (1976), essa abordagem avalia índices que utilizam uma linha de pobreza para cada dimensão (Tsui, 2002).

Nesse sentido, conforme Bourguignon e Chakravarty (2019) - um índice multidimensional geral - pode ser decomposto e cumpre os axiomas necessários, podendo ser definido como:

$$
P(X, z)=\frac{1}{n} \sum_{i=1}^{n} f\left(\begin{array}{c}
\max \left\{0 ;\left(1-\frac{x_{i, 1}}{z_{1}}\right)\right. \\
\ldots, \max \left\{0 ;\left(1-\frac{x_{i, 1}}{z_{1}}\right)\right.
\end{array}\right)
$$

Por abordagem vinculativa para definir $f(\cdot)$, e usando uma variação no índice de Foster, Greer e Thorbecke (1984) para capturar a severidade da pobreza, a pobreza multidimensional pode ser medida da seguinte forma:

$$
P(X, z)=\frac{1}{n} \sum_{i=1}^{n} f\left[\frac{1}{m} \sum_{i=1}^{n} X_{\hat{i}, k^{2}}\right]
$$

É possível concluir, a partir da equação (2), que as dimensões não são substituíveis, mas se inter-relacionam com o nível geral de pobreza, o que é consistente com uma abordagem baseada em dimensões de bem-estar. Além disso, no nível individual, mais peso é dado para as dimensões que apresentam um maior Gap de privação e, em seguida, mais peso é atribuído a pessoas com maiores níveis de privação. Isto faz com que o índice seja sensível para a distribuição de pobreza. A pobreza a nível individual se define por: $P_{i} \frac{1}{m} \sum_{i=1}^{n} X_{\hat{\imath}, k^{2}}$, com um valor máximo de 1 (pobreza total) e um mínimo de 0 (sem pobreza).

Vale destacar que em cada dimensão foram calculadas duas categorias, a saber: (i) índice de incidência (proporção de pobres) e (ii) índice de privação para a região e grupos demográficos. No caso do índice de incidência é considerado que todas as pessoas que estão abaixo do limite em pelo menos uma variável, sofrem privação (enforque de união), com base na seguinte regra:

$$
\text { Sofre Privação }=\left\{\begin{array}{l}
\text { Sim; se } X_{\hat{\imath}, k}>0 \\
\text { Não; se } X_{\hat{\imath}, k}<0
\end{array}\right.
$$

No tocante ao nível de privação, é levado em consideração que há um nível de privação para cada pessoa em cada indicador, e é medido diretamente por $X_{i, k}^{\hat{l}}$, embora o nível privação individual em cada dimensão é determinada pela função de agregação $g_{k}($.$) como segue:$

$$
X_{i, k}=\frac{1}{p} \sum_{I=1}^{p} X_{i, k}^{I}
$$


Desse modo, os indicadores se agregam a nível para cada dimensão sobre a base da seguinte função: $X_{i, k}=g_{k}\left(X_{i, k}^{l}, \ldots, X_{i, k}^{p}\right)$ para as variáveis $l=\{1, \ldots, p\}$, onde a função $g_{k}($.$) é específica de cada dimensão k$. Todos os indicadores têm o valor máximo de 1 (nível alcançado) e um valor mínimo de 0 (privação total), sendo essa definição utilizada para reduzir os problemas de descontinuidade.

Por fim, tem-se o nível de privação global para cada dimensão que pode ser decomposto por meio da função:

$$
X_{\hat{k}}=\frac{1}{n} \sum_{i=1}^{n} X_{\hat{\imath}, k}
$$

Para medir o nível de privação global $\left(X_{\hat{\imath}, k}\right)$ usa-se (6) em cada dimensão e define o nível de privação médio entre as variáveis. Para identificar o nível de privação de cada dimensão, a reformulação dos índices é feita usando a fórmula: $X_{\hat{\imath}, k}=1-X_{i, k}$, onde o nível de privação $X_{\hat{\imath}, k}$ é interpretado como a diferença relativa entre o nível individual de $X_{i, k}$ e o limite da privação $Z_{k}=1$, com um valor máximo de 1 (privação total) e um mínimo de 0 (sem privação).

\section{Resultados e Discussão}

\subsection{Nível de privação da pobreza no Nordeste Brasileiro no período de 2009 a 2015}

Para analisar a pobreza de um país, região ou estado é necessário medi-la. Conforme Sen (2000), a análise da pobreza deve concentrar-se nas possibilidades que tem um indivíduo de funcionar, mais do que nos resultados obtidos com esse funcionamento. O caráter multidimensional da pobreza exige a construção de um índice que tenha uma abordagem multidimensional e, portanto, que englobe as diferentes dimensões de privação.

Conforme Alkire (2002), a necessidade de especificar dimensões para o estudo da pobreza surge de diversas causas: (i) a primeira ocorre em função do propósito multidimensional, pois a pobreza precisa ser minimizada e o bem-estar precisa ser melhorado em diferentes aspectos; (ii) a segunda razão é a pratica e relacionar-se com a necessidade de metodologia efetivas para avaliar os tradeoffs; (iii) a terceira é que um grupo de dimensões podem ajudar a identificar impactos não intencionais. A razão final diz respeito à determinação de dimensões que sejam facilmente entendidas.

A seguir é apresentado, conforme cada dimensão, a análise do nível de privação dos indivíduos dos estados nordestinos (Tabela 2). 
Tabela 2 - Incidência de privação no Nordeste brasileiro, 2009-2015 (\%).

\begin{tabular}{|c|c|c|c|c|c|c|c|}
\hline Dimensões/Variáveis & 2009 & 2011 & 2012 & 2013 & 2014 & 2015 & Variação \\
\hline Dimensão 1: Água e Alimentos & 21,82 & 19,91 & $\mathbf{1 7 , 8 3}$ & 19,17 & 17,77 & 19,17 & -12.14 \\
\hline Água na Moradia & 15,63 & 13,83 & 12,97 & 13,69 & 13,48 & 13,73 & -12.16 \\
\hline Capacidade de compra de alimentos & 8,48 & 7,92 & 6,29 & 7,20 & 5,59 & 6,90 & -18.63 \\
\hline Dimensão 2: Comunicação e Informação & 84,47 & 76,67 & 72,17 & 69,75 & 69,21 & 71,23 & -15.67 \\
\hline Telefone & 23,13 & 13,27 & 10,97 & 8,94 & 7,43 & 8,11 & -64.94 \\
\hline Televisão & 3,99 & 2,71 & 2,37 & 2,36 & 2,07 & 2,25 & -43.61 \\
\hline Computador & 79,57 & 71,57 & 67,22 & 64,04 & 63,29 & 65,88 & -17.20 \\
\hline Internet & 84,30 & 76,37 & 71,85 & 69,47 & 68,94 & 70,97 & -15.81 \\
\hline Dimensão 3: Educação & 95,39 & 94,75 & 94,56 & 93,98 & 93,85 & 93,46 & -2.02 \\
\hline Ensino Primário & 84,00 & 83,18 & 83,50 & 83,09 & 82,99 & 83,13 & -1.04 \\
\hline Ensino Fundamental incompleto & 93,23 & 92,32 & 92,28 & 91,68 & 91,48 & 91,23 & -2.15 \\
\hline Ensino Fundamental completo & 94,36 & 93,46 & 93,43 & 92,79 & 92,57 & 92,21 & -2.28 \\
\hline Ensino Médio incompleto & 95,28 & 93,56 & 94,40 & 93,77 & 93,60 & 93,22 & -2.16 \\
\hline Ensino Médio Completo & 95,39 & 94,74 & 94,56 & 93,97 & 93,84 & 93,45 & -2.03 \\
\hline Proporção de crianças na escola & 2,97 & 2,36 & 2,01 & 1,84 & 2,06 & 2,04 & -31.31 \\
\hline Dimensão 4: Condições da Moradia & 31,74 & 30,68 & 30,00 & $\mathbf{3 0 , 8 2}$ & 30,79 & 29,02 & -8.57 \\
\hline Tipo de Moradia & 24,25 & 23,71 & 24,02 & 25,18 & 25,66 & 24,20 & -0.21 \\
\hline Iluminação & 0,78 & 0,55 & 0,37 & 0,26 & 0,17 & 0,15 & -80.77 \\
\hline Material da Parede & 2,65 & 2,77 & 1,91 & 2,12 & 1,78 & 1,77 & -33.21 \\
\hline Material do Teto & 0,87 & 1,06 & 0,84 & 0,86 & 0,82 & 0,71 & -18.39 \\
\hline $\mathrm{N}^{\mathrm{o}}$ de pessoas por dormitório & 7,13 & 6.28 & 5,57 & 5,18 & 5,26 & 4,62 & -35.20 \\
\hline Dimensão 5: Saúde & 64,95 & 59,38 & 59,02 & 59,55 & 58,47 & 57,00 & -12.24 \\
\hline Esgotamento Sanitário & 64,55 & 58,67 & 58,15 & 58,88 & 58,01 & 56,25 & -12.86 \\
\hline Condição Sanitária & 18,69 & 18,78 & 18,46 & 18,78 & 18,50 & 18,48 & -1.12 \\
\hline Eliminação do lixo & 0,74 & 0,68 & 0,58 & 0,50 & 0,51 & 0,36 & -51.35 \\
\hline Dimensão 6: Trabalho e Demografia & 71,15 & 68,35 & 68,85 & 67,38 & 66,49 & 67,96 & -4.48 \\
\hline Trabalho Precário & 65,34 & 62,27 & 63,33 & 61,78 & 60,59 & 62,66 & -4.10 \\
\hline Razão de dependência por domicílio & 18,76 & 18,99 & 18,82 & 18,53 & 18,26 & 18,64 & -0.64 \\
\hline
\end{tabular}

Fonte: Elaboração própria a partir dos dados da PNADs (2009 a 2015).

Conforme Leite et al (2016), para os níveis de privação da pobreza é preciso considerar duas importantes frentes: (i) necessidades básicas e (ii) capacidades. "Na primeira, o grau de pobreza é identificado pelos indicadores de acesso" [...] e a segunda consideração com base em Sen (1985), admite a importância da heterogeneidade dos indivíduos” (Leite et al, 2016, p. 69).

A Dimensão 1 foi construída a partir de duas variáveis, a saber: (i) água na moradia e (ii) capacidade de compra de alimentos. Um fator a ser considerado é a origem da água no domicílio; "se o abastecimento for da rede proveniente geral de distribuição, o domicílio é considerado não privado. Contudo, se for oriundo de poço ou nascente, ou outra providência, é denominado privado do bem" (Silva; Sousa; Araújo, 2017, p. 227). Notou-se, a partir dos dados expostos (Tabela 2) que houve uma queda da privação do acesso à agua nos domicílios da Região Nordeste no período de 2009 a 2016. Em 2009 , por exemplo, cerca de 15,63\% não tinha acesso à água potável proveniente da rede geral de distribuição, já em 2015 13,73\% não possuíam. Portanto, nota-se um pífio decrescimento da privação desse indicador.

De acordo com Maluf (2006), a pobreza é o determinante preponderante de a insegurança alimentar, isto é, a inexistência de acesso regular a uma alimentação adequada, é a égide para os fenômenos de fome e da subnutrição. É importante observar que na dimensão como um todo o impacto da redução é perceptível em conjunto e nos indicadores isolados. Portanto, houve uma redução de 21,82\% em 2009 para 19,17\% em 2015, diminuição de 2,65\% da pobreza multidimensional no Nordeste brasileiro na dimensão água e alimentos.

Para Rufino et al. (2016), a ausência de água adequada na moradia contribui para o aumento de patologias, a exemplo de Doença Diarreia Aguda (DDA). Dado que, “os surtos de DDA possuem um forte componente de veiculação hídrica, ainda que também possam estar associados à contaminação de alimentos e envolver uma grande variedade de agentes patogênicos (vírus, bactérias e parasitas) circulantes no ambiente" (Rufino et al, 2016, p. 778). 
Essa tendência à pobreza na referida dimensão também foi verificada em Brandolini e D’Alessio (1998), Carvalho, Kerstenetzky e Del-Vecchio (2007), Ottonelli et al. (2013), visto que, mesmo com os resultados divergindo pelo uso de diferentes metodologias, eles corroboraram com o estudo na medida em que chegaram à conclusão de que a falta de acesso à água e renda é uma das principais causas da pobreza, sendo a renda, a maior privação sofrida pelos indivíduos.

Observa-se que a privação na dimensão da comunicação e informação é medida por quatro variáveis: a posse de telefone, televisão, computador, e acesso à internet. É considerado como indivíduos privados os que não possuem meios de informação para a vivência na sociedade atual. Entretanto, Mideros (2012) afirma que a posse desses meios de comunicação não implica um verdadeiro acesso e uso deles, nem nos diz nada sobre a qualidade das informações acessadas.

Na presente análise, nota-se que em 2009, por exemplo, o nível de privação era de 79,57\% para computadores e de 84,30\% para internet e, em 2015, respectivamente, de 65,88\% e 70,97\%. Assim, é possível observar que a redução da privação esteja correlacionada a difusão tecnológica ocorrida nos últimos anos que proporcionou uma maior facilidade ao acesso às novas tecnologias de comunicação (Santos, 2003).

A dimensão educação foi construída por meio de 6 indicadores, os quais levam em conta o número de anos de estudo exigidos para conclusão de cada etapa do ensino. Os indicadores com maior privação concentram-se na dimensão educação. Justamente por conta de a pesquisa levar em consideração as prerrogativas da Lei de Diretrizes e Bases da Educação (Lei 9.394/1996), que estabelece as diretrizes e bases da educação nacional, na qual afirma que há um nível de escolaridade mínima requerida para uma determinada faixa etária.

Observa-se uma pequena redução na privação, segundo a dimensão da educação, em 2009 era de 95,39\%, passando para 93,46\% em 2015. O ensino que apresentou uma redução maior na privação foi o ensino fundamental completo, reduzindo 2,15\% de 2009 para 2015. Logo em seguida, o ensino médio incompleto (2,06\%), ensino fundamental incompleto (2\%) e o ensino médio completo $(1,94 \%)$.

Conforme Leite et al (2016, p. 19), "diante deste cenário de adversidade, políticas de acesso à educação de qualidade, em especial nas áreas rurais, são de fundamental importância à redução das desigualdades de educação e renda e, consequentemente, dos níveis de pobreza.". Desse modo, investir em políticas públicas educacionais é contribuir para a redução de funcionamentos básicos que fomentam a redução da pobreza multidimensional.

Na dimensão 4, moradia, conforme a Constituição Federal (1988) é um dos direitos fundamentais de todos os indivíduos e este é preconizado no artigo 6. Entretanto, milhares de famílias em situação de vulnerabilidade social vivenciam violações desse direito fundamental. Ao contrário da renda monetária, Rissin et al. (2006), afirmam que as condições habitacionais são objetivamente constatadas pelo observador, além de já terem sido utilizadas de maneira satisfatória tanto por autores nacionais - Sousa (1992) e Benício (1997) - bem como por autores internacionais - Molina et al. (1989), Bóbak et al. (1994) e Willett (1992) - para analisar o fator de risco de doenças. Portanto, as condições habitacionais representam, assim, a relação de cada indivíduo com seu ambiente físico, biótico e social e podem contribuir na identificação dos níveis de pobreza.

No período de 2009 a 2015 houve uma redução da privação de moradia na Região Nordeste, conforme destaca os dados da Tabela $2(-8,57)$. Outro fator preocupante é o caso em que, quase um terço da população não possuía moradia própria já quitada. Em 2015, por exemplo, cerca 4,62\% da população vivia em domicílios com mais de três pessoas por quarto. O referido indicador foi o segundo que obteve a maior redução de privação para o período $(-35,20)$.

Segundo Monteiro e Veras (2017, p. 2): “a garantia de acesso à moradia a parcela da população considerada de baixa renda é indispensável para atender as necessidades dos grupos sociais mais vulneráveis”. Além disso, conforme Silva, Sousa e Araújo (2017), [...] "a falta de acesso a condições dignas de moradia é um dos agravantes da pobreza multidimensional". Portanto, "são necessárias políticas habitacionais eficazes e contínuas que permitam a inclusão destes indivíduos na cidade e a sua inserção na sociedade" (Monteiro \& Veras, 2017, p. 2). 
Analisando a dimensão saúde, verifica-se que houve uma redução da sua privação, de 64,95\% em 2009, para 57,00\% em 2015, assim sendo, observa-se uma queda de $-12,24 \%$ no período observado, dado uma queda de todos os indicadores em análise. Dentre os indicadores analisados o esgotamento sanitário foi o que obteve maior redução de privação, com uma queda de $-12,86 \%$. Nessa perspectiva, Teixeira, Gomes e Souza (2011, p 198), relatam que "a partir de 2003, os investimentos em saneamento básico no Brasil aumentaram expressivamente [...]”. Além disso:

Mais recentemente, a Lei 11.445 (Brasil, 2007a), chamada Lei do Saneamento Básico, estabeleceu que os serviços públicos de saneamento básico serão prestados com base em 12 princípios fundamentais, destacando-se: a universalização do acesso; a integralidade dos diversos serviços de saneamento básico; a prestação dos serviços de abastecimento de água, esgotamento sanitário, limpeza urbana e manejo dos resíduos sólidos realizados de formas adequadas à saúde pública e à proteção do meio ambiente; e a disponibilidade, em todas as áreas urbanas, de serviços de drenagem e manejo das águas pluviais adequados à saúde pública e à segurança da vida e dos patrimônios público e privado (Teixeira et al., 2011, p. 198).

A falta de acesso ou o acesso inapropriado de saneamento básico pode ocasionar sérios danos à saúde dos indivíduos, principalmente no que diz respeito à saúde básica (Heller, 1997). Desse modo, a melhora da cobertura por serviços de saneamento básicos provoca melhorias nos indicadores de saúde (Teixeira et al., 2011). Além disso, conforme Marmot (2015, p. 3):

[...] As desigualdades na saúde geram desiguais possibilidades de usufruir dos avanços científicos e tecnológicos ocorridos nesta área, bem como diferentes chances de exposição aos fatores que determinam a saúde e a doença e por fim as diferentes chances de adoecimento e morte. Da mesma forma que as desigualdades sociais, as da em saúde têm persistido em todos os países independente do grau de desenvolvimento alcançado.

Desse modo, acredita-se que a queda dos indicadores possa refletir os efeitos desses investimentos. Por fim, é válido lembrar dos Objetivos de Desenvolvimento do Milênio - ODM, os quais foram implementados no período de 2000 a 2015 e, portanto, contribuíram para o cenário em questão (Ravallion, 2011).

A privação do trabalho é medida por trabalho precário. É denominado trabalho precário aquele no qual o trabalhador não era segurado da previdência social nem contribuinte de outro instituto de previdência. E demografia, a razão de pessoas dependentes por domicílio, sendo elas na faixa etária menor de 14 anos e maiores de 60.

Lima (2002, p. 109) observa que:

No Nordeste, o novo proletariado é formado por trabalhadores que circulam entre cooperativas e unidades industriais, em suas distintas formas - unidades fabris, empresas terceirizadas, cooperativas - tem significado a inclusão de partes da população, que vivia numa economia de subsistência, à produção capitalista e ao consumo, a partir de ganhos monetários relativamente regulares. Todavia, a inclusão insere-se num contexto de flexibilização da produção e das relações de trabalho, o que resulta em formas precarizadas de assalariamento - com direitos restritos ou sem direito algum.

No tocante a razão de dependência por domicílio apresenta uma taxa de privação considerada baixa, 18,64\% da população em 2015 apresenta alguma relação dependência. Na análise regional da dimensão, houve uma queda na privação, de 71,15\% em 2009 para 67,96\% em 2015. Portanto, apesar da redução (-4,48\%) a privação nesta dimensão é bem expressiva.

Acredita-se que a crise econômica a partir de 2008 tenha contribuído para as oscilações dos indicadores em questão (Proni, 2013; Silva et al., 2020). No período em questão vale destacar os resultados do ano de 2014, observa-se que no referido ano os indicadores apresentaram uma pequena retração em relação ao ano anterior, apesar de crescerem em 2015. A justificativa teórica para tal situação é o agravamento da crise econômica a partir de 2015 (Cacciamali \& Tatei, 2016). 


\subsection{Gaps de privação nos estados nordestinos nos anos 2009 e 2015}

Como já reportado na seção dos procedimentos metodológicos, os gaps, ou comumente chamados de lacunas de privação, representam a distância entre indivíduos pobres e um determinado limite de pobreza total. Os Gaps variam entre 0 e 1 e foram calculados para as respectivas dimensões estudadas, quando multiplicado por 100, representa o percentual do limite de pobreza total (Silva et al, 2016; Silva et al., 2017).

$\mathrm{Na}$ Tabela 3, os números mostram a diferença média para diferentes áreas e grupos populacionais. Observa-se que a pobreza na Região Nordeste, nesta dimensão é um problema, sobretudo, nas áreas rurais. Em 2015, por exemplo, o destaque maior de privação na dimensão “Água e Alimentos”, ocorreu na área rural (18,04\%). Na área metropolitana e urbana os níveis de privação são relativamente menores, com valores, respectivamente, de 5,19\% e 5,89\%, no mesmo período.

Tabela 3 - Região Nordeste: Gap da privação por dimensão, 2009 e 2015. (\%).

\begin{tabular}{|c|c|c|c|c|c|c|}
\hline \multirow[b]{2}{*}{ Estados/Área/Grupo } & \multicolumn{2}{|c|}{ Água e Alimentos } & \multicolumn{2}{|c|}{ Comunicação e Informação } & \multicolumn{2}{|c|}{ Educação } \\
\hline & 2009 & 2015 & 2009 & 2015 & 2009 & 2015 \\
\hline Reg. Nordeste & 10,11 & 8,50 & 47,75 & 36,80 & 85,27 & 84,35 \\
\hline Maranhão & 16,45 & 14,91 & 52,88 & 44,60 & 85,24 & 84,21 \\
\hline Piauí & 7,25 & 4,28 & 49,21 & 39,60 & 84,22 & 83,43 \\
\hline Ceará & 9,48 & 9,00 & 47,47 & 38,33 & 84,86 & 85,08 \\
\hline Rio Grande do Norte & 7,01 & 6,24 & 45,54 & 32,68 & 85,76 & 83,60 \\
\hline Paraíba & 9,64 & 7,34 & 47,00 & 32,25 & 85,01 & 82,14 \\
\hline Pernambuco & 11,37 & 10,09 & 46,04 & 33,97 & 84,94 & 83,52 \\
\hline Alagoas & 15,28 & 13,16 & 50,01 & 38,75 & 85,66 & 84,56 \\
\hline Sergipe & 6,97 & 5,62 & 43,08 & 36,83 & 84,45 & 84,58 \\
\hline Bahia & 7,82 & 5,84 & 47,63 & 35,85 & 85,94 & 85,33 \\
\hline Metropolitano & 6,33 & 5,19 & 36,85 & 27,65 & 83,08 & 82,29 \\
\hline Urbano & 6,95 & 5,89 & 46,26 & 34,33 & 85,00 & 83,56 \\
\hline Rural & 22,89 & 18,04 & 63,51 & 51,59 & 88,35 & 88,25 \\
\hline Homens & 10,25 & 8,70 & 48,36 & 37,41 & 86,22 & 85,97 \\
\hline Mulheres & 9,97 & 8,32 & 47,17 & 36,53 & 84,39 & 82,85 \\
\hline Crianças & 12,79 & 10,67 & 51,27 & 39,59 & 77,63 & 77,64 \\
\hline Adolescentes & 11,42 & 9,81 & 48,98 & 36,57 & 84,90 & 83,55 \\
\hline Jovens & 9,88 & 8,74 & 45,79 & 34,89 & 89,44 & 87,43 \\
\hline Adultos & 8,80 & 7,55 & 45,45 & 34,69 & 85,42 & 83,91 \\
\hline Idosos & 8,08 & 6,76 & 53,58 & 45,09 & 93,71 & 93,54 \\
\hline Branca & 8,71 & 7,78 & 42,86 & 32,22 & 82,49 & 81,10 \\
\hline Não Branca & 10,70 & 8,77 & 49,83 & 38,50 & 86,46 & 85,56 \\
\hline \multirow[t]{2}{*}{ Estados/Área/Grupo } & \multicolumn{2}{|c|}{ Condições da Moradia } & \multicolumn{2}{|c|}{ Saúde } & \multicolumn{2}{|c|}{$\begin{array}{c}\text { Trabalho e } \\
\text { Demografia }\end{array}$} \\
\hline & 2009 & 2015 & 2009 & 2015 & 2009 & 2015 \\
\hline Reg. Nordeste & 6,92 & 6,04 & 27,99 & 25,03 & 42,05 & 40,64 \\
\hline Maranhão & 8,34 & 7,09 & 37,29 & 37,84 & 43,20 & 45,12 \\
\hline Piauí & 5,58 & 4,89 & 40,04 & 38,00 & 44,19 & 40,53 \\
\hline Ceará & 7,16 & 6,60 & 28,09 & 28,18 & 42,92 & 40,84 \\
\hline Rio Grande do Norte & 7,11 & 6,10 & 30,68 & 28,16 & 39,95 & 37,39 \\
\hline Paraíba & 7,08 & 7,68 & 25,69 & 19,68 & 42,76 & 41,25 \\
\hline Pernambuco & 6,93 & 5,83 & 24,88 & 20,13 & 41,36 & 39,22 \\
\hline Alagoas & 6,50 & 6,06 & 34,42 & 26,67 & 38,74 & 38,50 \\
\hline Sergipe & 6,79 & 6,16 & 20,39 & 22,18 & 41,70 & 39,55 \\
\hline Bahia & 6,45 & 5,18 & 23,73 & 19,57 & 42,18 & 40,94 \\
\hline Metropolitano & 6,97 & 5,89 & 14,21 & 12,49 & 38,56 & 34,87 \\
\hline Urbano & 6,88 & 6,48 & 22,71 & 17,57 & 44,01 & 41,57 \\
\hline Rural & 7,00 & 5,09 & 57,34 & 55,20 & 40,33 & 43,94 \\
\hline Homens & 6,95 & 6,09 & 28,75 & 25,88 & 41,46 & 40,19 \\
\hline Mulheres & 6,90 & 5,99 & 27,28 & 24,24 & 42,59 & 41,06 \\
\hline Crianças & 9,55 & 8,50 & 29,52 & 26,74 & 48,84 & 45,74 \\
\hline Adolescentes & 7,03 & 6,18 & 30,19 & 27,76 & 40,41 & 38,64 \\
\hline Jovens & 7,50 & 7,07 & 26,92 & 24,38 & 36,61 & 34,94 \\
\hline Adultos & 5,86 & 5,22 & 26,89 & 23,77 & 37,72 & 35,74 \\
\hline Idosos & 3,45 & 2,90 & 29,02 & 25,59 & 63,98 & 66,78 \\
\hline Branca & 6,42 & 5,85 & 25,45 & 22,71 & 40,03 & 38,95 \\
\hline Não Branca & 7,14 & 6,10 & 29,08 & 25,89 & 42,92 & 41,27 \\
\hline
\end{tabular}

Fonte: Elaboração pelos próprios autores a partir dos dados da PNADs. 
No tocante ao gap da dimensão de Comunicação e Informação, observa-se que houve retração em todos os indicadores, entre 2009 e 2015. No entanto, tanto em 2009, quanto em 2015, o Gap de privação da população rural nordestina $(51,59 \%)$ foi bem mais elevado do que das regiões metropolitana $(27,65 \%)$ e urbana $(34,33 \%)$.

Já na dimensão de educação, nota-se um maior Gap na área rural, quando comparadas com a metropolitana e urbana, situação essa já observada nas outras dimensões. Contrapondo-se a todos os resultados apresentados nas outras dimensões, a zona rural teve uma diminuição ínfima da privação de 2009 (88,35\%) para 2015 (88,25\%). Já nas áreas metropolitanas e urbanas observou-se um arrefecimento da privação em educação de 82,29\% e 83,56\% respectivamente no ano de 2015.

Na dimensão "Condições de Moradia", observa-se que houve uma redução maior do gap em áreas rurais. Ainda nesse mesmo período, entre os grupos etários, quem possui a menor privação é o grupo dos idosos, com apenas 2,90\%, e a maior é o grupo das crianças, com $8,50 \%$. As populações de raça não branca $(6,10 \%)$ têm Gap de maior privação do que a raça branca $(5,85 \%)$.

Na dimensão da "Saúde" o maior nível de privação está situado na área rural, em 2009, por exemplo, a lacuna de privação era de $57,34 \%$, e em 2015 , apesar da queda, é $55,20 \%$. Essa realidade indica que mais da metade na população rural da região nordeste apresenta privação de saneamento básico, situação essa que corrobora para piores indicadores de saúde (Teixeira; Gomes; Souza, 2011).

Contrapondo-se com todas as outras dimensões, na dimensão trabalho e demografia, as mulheres $(41,06 \%)$ apresentam um Gap privação maior que os homens (40,19\%), evidenciam-se mais ainda a diferença no mercado de trabalho entre homens e mulheres. Mesmo com uma redução, a situação ainda é considerada como alta privação. No grupo da faixa etária o resultado já é o esperado: maior privação para crianças e idosos, pois eles são dependentes e não trabalham. O menor Gap foi para o grupo dos jovens, com 34,94\%, em 2015. A população branca $(38,95 \%)$ possui uma lacuna de privação menor quando comparada com a raça não branca $(41,27 \%)$.

\subsection{Pobreza multidimensional por estados e grupos da Região Nordeste no Brasil no período de 2009 a 2015}

De acordo com Anand e Sen (1997), uma visão multidimensional da pobreza não trabalha apenas com um único indicador de pobreza, mas também mostra porque uma medida de pobreza baseada na renda sofre viés em suas análises. Estes consideram a pobreza como a pior forma de privação humana, que envolve não apenas as necessidades básicas, mas também as suas capacitações.

A tabela 4 mostra a pobreza multidimensional por estado e grupos no Nordeste, no período de 2009-2015. Os resultados demostram uma redução na pobreza multidimensional de 25,79\% em 2009, para 23,78\% em 2015, tendo uma variação de $-7,79 \%$. 
Tabela 4 - Pobreza Multidimensional por Estados e grupos da Região Nordeste do Brasil, 2009-2015 (\%).

\begin{tabular}{|c|c|c|c|c|c|c|c|}
\hline & \multicolumn{6}{|c|}{ Pobreza Multidimensional } & \multirow[b]{2}{*}{ Variação } \\
\hline & 2009 & 2011 & 2012 & 2013 & 2014 & 2015 & \\
\hline Região Nordeste & 25,79 & 24,46 & 24,18 & 23,80 & 23,53 & 23,78 & $-7,79 \%$ \\
\hline Maranhão & 28,12 & 27,54 & 27,70 & 26,88 & 26,86 & 27,10 & $-3,63 \%$ \\
\hline Piauí & 26,91 & 25,20 & 25,25 & 24,68 & 24,02 & 24,06 & $-10,59 \%$ \\
\hline Ceará & 25,40 & 24,71 & 24,48 & 23,84 & 23,84 & 24,48 & $-3,62 \%$ \\
\hline Rio Grande do Norte & 24,71 & 23,65 & 22,88 & 22,83 & 22,80 & 22,54 & $-8,78 \%$ \\
\hline Paraíba & 25,71 & 23,00 & 23,08 & 22,49 & 22,43 & 22,53 & $-12,37 \%$ \\
\hline Pernambuco & 25,39 & 23,48 & 22,97 & 22,84 & 22,62 & 22,92 & $-9,73 \%$ \\
\hline Alagoas & 26,55 & 25,26 & 24,32 & 24,58 & 23,88 & 24,23 & $-8,74 \%$ \\
\hline Sergipe & 24,04 & 23,64 & 22,75 & 22,50 & 23,02 & 22,92 & $-4,66 \%$ \\
\hline Bahia & 25,04 & 24,07 & 23,03 & 23,61 & 22,95 & 23,24 & $-7,19 \%$ \\
\hline Metropolitano & 21,72 & 20,66 & 20,32 & 20,08 & 19,91 & 20,26 & $-6,72 \%$ \\
\hline Urbano & 24,61 & 23,10 & 22,71 & 22,37 & 22,25 & 22,25 & $-9,59 \%$ \\
\hline Rural & 33,38 & 32,26 & 31,84 & 31,14 & 30,29 & 30,91 & $-7,40 \%$ \\
\hline Homens & 26,02 & 24,69 & 24,47 & 24,08 & 23,80 & 24,12 & $-7,30 \%$ \\
\hline Mulheres & 25,57 & 24,24 & 23,92 & 23,54 & 23,28 & 23,47 & $-8,21 \%$ \\
\hline Crianças & 25,32 & 23,87 & 23,29 & 22,70 & 22,41 & 22,72 & $-10,27 \%$ \\
\hline Adolescentes & 25,34 & 23,69 & 23,42 & 23,08 & 22,70 & 22,89 & $-9,67 \%$ \\
\hline Jovens & 25,61 & 24,23 & 23,98 & 23,46 & 23,21 & 23,40 & $-8,63 \%$ \\
\hline Adultos & 24,83 & 23,49 & 23,23 & 22,92 & 22,61 & 22,76 & $-8,34 \%$ \\
\hline Idosos & 33,12 & 32,25 & 32,24 & 32,00 & 31,73 & 32,15 & $-2,93 \%$ \\
\hline Branca & 24,19 & 23,10 & 22,50 & 22,29 & 21,96 & 22,30 & $-7,81 \%$ \\
\hline Não Branca & 26,47 & 25,03 & 24,86 & 24,39 & 24,13 & 24,33 & $-8,08 \%$ \\
\hline
\end{tabular}

Fonte: Elaboração própria a partir dos dados da PNADs (2009 a 2015).

Verifica-se que em média, não existe diferença considerável na pobreza entre os grupos de faixa etária e sexo. Contudo, houve uma redução em todos os grupos. A pobreza multidimensional é maior para os homens, embora a retração tenha sido maior para as mulheres $(-8,21 \%)$.

\subsection{Pobreza multidimensional da Região Nordeste por área no período de 2009 a 2015}

A Tabela 5 apresenta a proporção de pobres da Região Nordeste do Brasil, 2009-2015, entre rural e urbano. As áreas rurais de todos os Estados expõem uma dimensão bem superior de pobres quando comparadas com as áreas metropolitanas e urbanas. Confirmando o que Silva e Neder (2010) destacaram: a pobreza multidimensional nas áreas rurais do Brasil é mais significativa. Na Região Nordeste, a proporção de pobres na zona rural em 2015 é de 30,81\%, enquanto na zona urbana é de $21,63 \%$.

As áreas com maior percentual de pobreza multidimensional são dos estados do Maranhão (27,10\%), seguido por Ceará (24,48\%), Alagoas (24,23\%), Piauí (24,06\%) e Bahia (23,24\%), corroborando, assim, com os dados mostrados por Lacerda (2009), no qual afirma que a pobreza no Brasil tem um sólido componente regional. 
Tabela 5 - Pobreza Multidimensional na Região Nordeste por área e Estado, 2009-2015. (\%)

\begin{tabular}{|c|c|c|c|c|c|c|c|}
\hline & 2009 & 2011 & 2012 & 2013 & 2014 & 2015 & Variação \\
\hline Região Nordeste & 25,79 & 24,46 & 24,18 & 23,80 & 23,53 & 23,78 & -7.79 \\
\hline Urbano & 23,78 & 22,38 & 22,00 & 21,69 & 21,55 & 21,63 & -9.04 \\
\hline Rural & 33,27 & 32,14 & 31,74 & 31,04 & 30,21 & 30,81 & -7.39 \\
\hline Maranhão & 28,12 & 27,54 & 27,70 & 26,88 & 26,86 & 27,10 & -3.63 \\
\hline Urbano & 26,19 & 24,38 & 24,78 & 24,17 & 24,42 & 24,39 & -6.87 \\
\hline Rural & 36,15 & 34,20 & 33,27 & 32,31 & 31,55 & 32,62 & -9.76 \\
\hline Piauí & 26,91 & 25,20 & 25,25 & 24,68 & 24,02 & 24,06 & -10.59 \\
\hline Urbano & 24,92 & 23,67 & 23,56 & 22,78 & 22,40 & 22,49 & -9.75 \\
\hline Rural & 34,48 & 31,51 & 31,14 & 31,61 & 29,25 & 29,03 & -15.81 \\
\hline Ceará & 25,40 & 24,71 & 24,48 & 23,84 & 23,84 & 24,48 & -3.62 \\
\hline Urbano & 23,89 & 22,55 & 22,18 & 21,71 & 21,74 & 22,15 & -7.28 \\
\hline Rural & 32,29 & 32,22 & 32,28 & 30,69 & 30,64 & 31,56 & -2.26 \\
\hline Rio Grande do Norte & 24,71 & 23,65 & 22,88 & 22,83 & 22,80 & 22,54 & -8.78 \\
\hline Urbano & 23,21 & 22,22 & 21,31 & 21,10 & 21,10 & 20,81 & -10.34 \\
\hline Rural & 29,02 & 29,58 & 29,28 & 29,56 & 28,57 & 28,64 & -1.31 \\
\hline Paraíba & 25,71 & 23,00 & 23,08 & 22,49 & 22,43 & 22,53 & -12.37 \\
\hline Urbano & 23,45 & 21,63 & 21,45 & 20,81 & 20,98 & 20,74 & -11.56 \\
\hline Rural & 34,65 & 30,91 & 31,51 & 30,07 & 29,87 & 30,59 & -11.72 \\
\hline Pernambuco & 25,39 & 23,48 & 22,97 & 22,84 & 22,62 & 22,92 & -9.73 \\
\hline Urbano & 23,50 & 22,01 & 21,45 & 21,35 & 21,13 & 21,28 & -9.45 \\
\hline Rural & 33,24 & 31,89 & 31,10 & 31,10 & 30,18 & 30,60 & -7.94 \\
\hline Alagoas & 26,55 & 25,26 & 24,32 & 24,58 & 23,88 & 24,23 & -8.74 \\
\hline Urbano & 24,69 & 23,23 & 22,23 & 22,61 & 22,38 & 22,44 & -9.11 \\
\hline Rural & 32,03 & 31,69 & 30,44 & 30,36 & 28,31 & 29,97 & -6.43 \\
\hline Sergipe & 24,04 & 23,64 & 22,75 & 22,50 & 23,02 & 22,92 & -4.66 \\
\hline Urbano & 22,52 & 21,12 & 20,58 & 20,30 & 20,89 & 20,91 & -7.15 \\
\hline Rural & 32,39 & 31,10 & 29,07 & 28,89 & 28,90 & 28,22 & -12.87 \\
\hline Bahia & 25,04 & 24,07 & 23,03 & 23,61 & 22,95 & 23,24 & -7.19 \\
\hline Urbano & 22,90 & 21,83 & 21,48 & 21,27 & 20,78 & 20,86 & -8.91 \\
\hline Rural & 33,74 & 32,17 & 32,21 & 31,46 & 30,52 & 30,99 & -8.15 \\
\hline
\end{tabular}

Fonte: Elaboração própria a partir dos dados da PNADs (2009 a 2015).

De forma geral, observa-se que os estados que apresentam maior nível de privação são: (i) Maranhão; (ii) Ceará; (iii) Piauí e (iv) Bahia. Já os estados com as menores taxas da pobreza multidimensional são: Rio Grande do Norte, Paraíba, Sergipe e Pernambuco. O estado da Paraíba apresenta a menor proporção de pobres, em 2015 a proporção de pobres multidimensionais é de $22,53 \%$. A área rural, como todos os outros estados, apresenta também maiores níveis pobreza.

\section{Considerações Finais}

O presente estudo analisou o nível de pobreza multidimensional da Região Nordeste no período de 2009 a 2015 . A conclusão mais direta do estudo é que nos últimos anos houve redução da pobreza multidimensional na Região Nordeste no período em estudo. Esse contributo se encaixa no princípio da atividade ou da constante transformação de Jean Brunhes (1962, p. 27), pois para o autor "tudo se transforma em nosso redor; tudo diminui ou cresce"; no caso da pobreza nos estados nordestinos, no respectivo período, observa-se uma redução. Dentre os estados, dois merecem atenção maior: (i) Paraíba, por 
ser o estado que apresentou o menor nível de privação em 2015 e (ii) o Maranhão que apresentou maior nível de privação no mesmo ano.

No tocante as dimensões três merecem destaque: (i) Educação; (ii) Comunicação e Informação e (iii) Trabalho e Demografia. As referidas dimensões foram as que, mesmo com a retração no período, apresentam níveis preocupantes. Significa dizer que, mesmo com a redução no período, osindicadores ainda se encontram elevado e refletem o nível de privação dos cidadãos no tocante aos respectivos funcionamentos. Portanto, as políticas públicas de redistribuição de renda na Região Nordeste precisam ser elaboradas levando em consideração a situação de tais indicadores, tendo por base a proposta bottom-up de políticas públicas.

Para as análises separadas das áreas metropolitana, urbana e rural, o nível de pobreza foi mais intenso na região rural, onde as intensidades de pobreza foram sensivelmente maiores. Existem várias hipóteses para essa conclusão, como: existência de idosos no domicílio, mas sem qualquer aposentadoria, que, apesar de ser da área rural, as famílias podem não ter acesso à terra para o plantio de subsistência, ou, ainda, a única fonte de renda das famílias pode ser de algum Programa do Governo Federal. Contudo, não é suficiente para retirá-los da pobreza. Por outro lado, essa situação é menos preocupante na área metropolitana da região Nordeste.

Nesse sentido, o estudo mostrou que, ao considerar a mensuração da pobreza multidimensional pela ótica das seis dimensões estudadas, constatou-se que ela apresentou uma trajetória decrescente durante o período em estudo, éo evidenciam os resultados do trabalho no tocante a redução da pobreza multidimensional de 25,79\% em 2009 para 23,78\% em 2015. Diante disso, acredita-se que tal cenário tenha ocorrido devido ao crescente investimento das políticas públicas de redistribuição de renda, implementadas pelo Governo Federal a partir de 2003.

Partindo desta análise, por que o governo deveria usar a medição multidimensional da pobreza como instrumento para políticas públicas? O uso de indicadores de pobreza multidimensional é benéfico porque contribui para uma melhor identificação de qual dimensão a situação é mais alarmante e, portanto, políticas públicas sociais focalizadas na população mais pobre pode ser um parâmetro mais eficiente para a resolução de tal problemática. Além disso, a identificação de cada dimensão e cada indicador de privação contribui para a elaboração de políticas sociais específicas por parte dos governos, que seriam mais eficientes na solução dos problemas destacados aqui. Por isso, a análise multidimensional da pobreza realizada nos estados nordestinos é uma importante estratégia para orientar a elaboração, implementação e monitoramento de políticas sociais, as quais terão maior probabilidade de alcance de resultados mais efetivos.

Portanto, conclui-se que para reduzir a pobreza multidimensional devem-se adotar políticas públicas direcionadas especificamente para as dimensões que mais impactam a pobreza, sendo elas: educação, trabalho e demografia, comunicação e informação, e saúde. E, em seguida, uma melhor distribuição desses recursos entre os estados, diminuindo assim as disparidades regionais.

Como sugestão de futuras pesquisas, deve-se ser realizada uma investigação para compreender as relações entre proteção social, crescimento econômico, e a redução da desigualdade sobre redução da pobreza multidimensional. Uma vez que, o índice utilizado na presente pesquisa aponta tais disparidades regionais, porém, deve ser feito um estudo teórico mais aprofundado para evidenciar as peculiaridades da pobreza dentro de cada estado da região Nordeste do Brasil. Logo, deve-se ser continua à procura de novos dados que visem melhorar os indicadores utilizados para medir cada uma das dimensões, e assim, mensurar qual tem mais impacto na pobreza multidimensional nordestina.

\section{Referências}

Anand, S., \& Sen, A. (1997). Concepts or human development and poverty! A multidimensional perspective. United Nations Development Programme, Poverty and human development: Human development papers, 1-20. 
Benício, M. H. D. A., \& Monteiro, C. A. (1997). Desnutriçäo infantil nos municípios brasileiros: risco de ocorrência. In Desnutriçäo infantil nos municípios brasileiros: risco de ocorrência (pp. 274-274).

Bobák, M., Kríz, B., Leon, D. A., Dánova, J., \& Marmot, M. (1994). Socioeconomic factors and height of preschool children in the Czech Republic. American Journal of Public Health, 84(7), 1167-1170.

Bourguignon, F., \& Chakravarty, S. R. (2019). The measurement of multidimensional poverty. In Poverty, social exclusion and stochastic dominance (pp. 83107). Springer, Singapore.

Brandolini, A., \& D’Alessio, G. (1998). Measuring well-being in the functioning space. In General Conference of The International Association for Research in Income and Wealth, Cracow, Poland.

do Brasil, S. F. (1988). Constituição da república federativa do Brasil. Brasília: Senado Federal, Centro Gráfico. http://www.planalto.gov.br/ccivil_03/constituicao/constituicaocompilado.htm.

Brunhes, J. (1962). Geografia humana. Rio de Janeiro: Editora Fundo de Cultura.

Cacciamali, M. C., \& Tatei, F. (2016). Mercado de trabalho: da euforia do ciclo expansivo e de inclusão social à frustração da recessão econômica. Estudos avançados, 30, 103-121.

Caldas, R. D. M., \& Sampaio, Y. D. S. B. (2015). Pobreza no nordeste brasileiro: uma análise multidimensional. Revista de Economia Contemporânea, 19, 7496.

Carvalho, M., Kerstenetzky, C. L., \& Del Vecchio, R. (2007). Uma aplicação da teoria dosconjuntos fuzzy na pobreza: o caso das Regiões Metropolitanas do Sudeste brasileiro-2000. In: XXXV Encontro Nacional De [Proceedings of the 35th Brazilian Economics Meeting] (No. 001). ANPEC - Associação Nacional dos Centros de Pós-graduação em Economia [Brazilian Association of Graduate Programs in Economics]. http://www.anpec.org.br/encontro2007/artigos/A07A001.pdf.

Castro, J. D. (1980). Geografia da fome (o dilema brasileiro: pão ou aço). rev. Antares.

Caetano, Y. D., \& de Souza Castro, M. (2021). Um estudo sobre a pobreza multidimensional no estado do Ceará no período de 2005 a 2015. Práticas Educativas, Memórias e Oralidades-Rev. Pemo, 3(3), e337171-e337171.

Brasil, Lei no 9.394, de 20 de dezembro de 1996. Estabelece as diretrizes e bases da educação nacional. Brasília: Presidência da República. http://www.planalto.gov.br/ccivil_03/leis/19394.htm.

Foster, J., Greer, J., \& Thorbecke, E. (1984). A class of decomposable poverty measures. Econometrica: journal of the econometric society, 761-766.

Heller, L. (1997). Saneamento e Saúde-OPAS-OMS. Representação do Brasil, Brasília.

Hoffmann, R. (2006). Transferências de renda e a redução da desigualdade no Brasil e cinco regiões entre 1997 e 2004. Revista Econômica, 8(1).. In: Barros, R. P. D. O., Foguel, M. N. O., \& Ulyssea, G. O. (2006). Desigualdade de renda no Brasil: uma análise da queda recente.

Kageyama, A., \& Hoffmann, R. (2006). Pobreza no Brasil: uma perspectiva multidimensional. Economia e Sociedade, 15(1), 79-112.

Leite, Á. R., Silva, A. F. D., Araújo, J. A. D., \& Santana, G. U. S. (2016). A pobreza multidimensional no estado da Bahia diminuiu? Evidências a partir da abordagem de Bourguignon E Chakravarty. Revista de Economia Contemporânea, 20, 177-200.

Lima, J. C. (2002). As artimanhas da flexibilização: o trabalho em cooperativas de produção industrial. Terceira Margem.

Maluf, R. S. (2006). Segurança alimentar e fome no Brasil-10 anos da Cúpula Mundial de Alimentação. Ceresan, Relatórios Técnicos, (2).

Marmot, M. (2015). The health gap: the challenge of an unequal world. The Lancet, 386(10011), 2442-2444.

Mideros, A. (2012). Ecuador: defining and measuring multidimensional poverty, 2006-2010. Cepal Review.

Molina, M. C. B., Gross, R., Schell, B., Leão, M. A. C., Strack, U., \& Brunken, B. (1989). Nutritional status of children of urban low-income communities, Brazil (1986). Revista de Saúde Pública, 23, 89-97.

Monteiro, A. R., \& Veras, A. T. D. R. (2017). A questão habitacional no Brasil. Mercator (Fortaleza), 16.

Mundial, B. (1990). Informe sobre el desarrollo mundial 1990. La pobreza. In Informe sobre el desarrollo mundial 1990. La pobreza (pp. 284-284).

Ottonelli, J., da Silva, J. L. M., \& Marin, S. R. (2013). Desenvolvimento humano no Nordeste: um estudo sobre a influência de indicadores sociais no IDH-M (1991 e 2000). Revista Economia e Desenvolvimento.

Proni, M. W. (2013). Trabalho decente e vulnerabilidade ocupacional no Brasil. Economia e Sociedade, 22, 825-854.

Prodanov, C. C. \& Freitas, E. C. (2013). Metodologia do trabalho científico: métodos e técnicas da pesquisa e do trabalho acadêmico. Novo Hamburgo: Feevale. e2.

Ravallion, M. (2011). On multidimensional indices of poverty. The Journal of Economic Inequality, 9(2), $235-248$.

Rissin, A., Batista Filho, M., Benício, M. H. D. A., \& Figueiroa, J. N. (2006). Condições de moradia como preditores de riscos nutricionais em crianças de Pernambuco, Brasil. Revista Brasileira de Saúde Materno Infantil, 6, 59-67.

Rocha, S. (1995). Governabilidade e pobreza: o desafio dos números. 
Research, Society and Development, v. 10, n. 17, e257101725129, 2021

(CC BY 4.0) | ISSN 2525-3409 | DOI: http://dx.doi.org/10.33448/rsd-v10i17.25129

Rufino, R., Gracie, R., Sena, A., Freitas, C. M. D., \& Barcellos, C. (2016). Surtos de diarreia na região Nordeste do Brasil em 2013, segundo a mídia e sistemas de informação de saúde-Vigilância de situações climáticas de risco e emergências em saúde. Ciência \& Saúde Coletiva, 21, 777-788.

Santos, A. Q. (2003, October). Inclusão digital e desenvolvimento local no Brasil. In Congresso Internacional Del Clad Sobre La Reforma Del Estado Y De La Administración Pública (Vol. 8).

Sen, A. K. (2000). Desenvolvimento como liberdade. Companhia das Letras.

Sen, A. (1996). Economic reforms, employment and poverty: Trends and options. Economic and Political Weekly, 2459-2477.

Sen, A. (1985). A sociological approach to the measurement of poverty: a reply to Professor Peter Townsend. Oxford Economic Papers, 37(4), 669-676.

Silva, A. F. D., Araujo, J. A. D., Justo, W. R., \& Campos, K. C. (2017). Análise da pobreza multidimensional no Brasil no período de 2009 a 2015.

Silva, J. J. D., Bruno, M. A. P., Silva, D. B., \& Nascimento, D. (2020). Pobreza multidimensional no Brasil: uma análise do período 2004-2015. Brazilian Journal of Political Economy, 40, 138-160.

Silva, A. M., \& Neder, H. D. (2010). Abordagem das capacitações: um estudo empírico sobre pobreza multidimensional no Brasil. In conferência latino americana e caribenha sobre abordagem das capacitações e desenvolvimento humano (Vol.3). http://www.pucrs.br/eventos/alcadeca/download/abordagemdas-capacitacoes-um-estudo-empirico-sobrepobreza.pdf.

Silva, A. M. R., Lacerda, F. C. C., \& Neder, H. D. (2011). A evolução do estudo da pobreza: da abordagem monetária à privação de capacitações. Bahia Análise \& Dados, 509.

Silva, A. F. D., Sousa, J. S. D., \& Araujo, J. A. (2017). Evidences on multidimensional poverty in the northern region of Brazil. Revista de Administração Pública, 51, 219-239.

Silva, A. F. D., Araujo, J. A. D., Campelo, G. L., Vasconcelos, J. C., \& Silva, J. C. D. (2016). Análise da pobreza multidimensional no Brasil.

da Silva, A. F., Araujo, J. A., Sobral, E. F. M., \& de Sousa, J. S. (2017). A pobreza no Rio Grande do Sul: evidências a partir de uma análise multidimensional do período 2007-14. Ensaios FEE, 38(3), 597-624.

Sousa, F. J. P. D. (1992). Pobreza, desnutriçäo e mortalidade infantil: condicionantes sócio-econômicos. In Pobreza, desnutriçäo e mortalidade infantil: condicionantes sócio-econômicos (pp. 129-129).

Teixeira, J. C., Gomes, M. H. R., \& Souza, J. A. D. (2011). Análise da associação entre saneamento e saúde nos estados Brasileiros: estudo comparativo entre 2001 e 2006. Engenharia Sanitaria e Ambiental, 16, 197-204.

Torres, R. S., Cifuentes, L. M., \& Murillo, L. M. (2020). Estimación alternativa de la pobreza multidimensional en Colombia. Revista de Economía Institucional, 22(43), 137-168.

Tsui, K. Y. (2002). Multidimensional poverty indices. Social choice and welfare, 19(1), 69-93.

Vasconcelos, F. D. A. G. D. (2008). Josué de Castro and The Geography of Hunger in Brazil. Cadernos de saude publica, 24(11), $2710-2717$.

Willett, W. (2012). Nutritional epidemiology (Vol. 40). Oxford university press. 